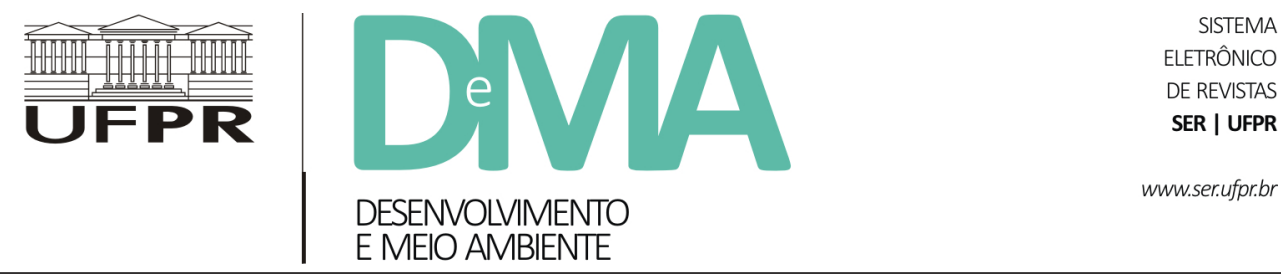

\title{
Modificações do licenciamento ambiental em Minas Gerais: avanço ou retrocesso?
}

\section{Modifications of environmental licensing in Minas Gerais: advance or regression?}

\author{
Maria Rita Raimundo e ALMEIDA ${ }^{1 *}$, Anne Caroline MALVESTIO ${ }^{2}$, Yara Rosa BERNADI ${ }^{3}$ \\ ${ }^{1}$ Universidade Federal de Itajubá (UNIFEI), Itajubá, MG, Brasil. \\ ${ }^{2}$ Universidade Federal de Uberlândia (UFU), Uberlândia, MG, Brasil. \\ ${ }^{3}$ Universidade de São Paulo (USP), São Paulo, SP, Brasil. \\ *E-mail de contato: maria.rita.ralmeida@gmail.com
}

Artigo recebido em 18 de abril de 2019, versão final aceita em 30 de setembro de 2019.

RESUMO: $\quad$ Apesar de a Avaliação de Impactos Ambientais (AIA) e o Licenciamento Ambiental (LA) serem importantes instrumentos de gestão ambiental, eles ainda recebem críticas pela falta de clareza sobre seus benefícios. Neste contexto, a simplificação e a eficiência destes instrumentos têm sido preocupações recorrentes. No Brasil, projetos de lei têm tramitado no cenário nacional e tem havido nos estados iniciativas de simplificação. Este é o caso de Minas Gerais (MG), onde diversas mudanças nas normas legais que regem o sistema de LA e AIA foram feitas entre 2016 e 2018. Assim, este artigo objetivou analisar tais mudanças, possibilitando inferir sobre potenciais benefícios ou prejuízos delas decorrentes para o cumprimento dos objetivos dos instrumentos. Para isso, realizou-se uma análise documental das normas legais, atuais e antigas, que tratam do sistema de AIA e LA em MG, levantando as modificações e avaliando-as frente às boas práticas da AIA, presentes na literatura. As modificações aconteceram em praticamente todas as etapas do processo, sendo que algumas representam importantes avanços (uso de recursos digitais e online, inclusão de critérios locacionais na triagem, alteração de parâmetros para definição do porte das atividades e criação de um núcleo de fiscalização e monitoramento), enquanto outras precisam ser observadas com cautela (dispensa da renovação da Licença de Operação para algumas atividades, diminuição da participação do COPAM na tomada de decisão e o significativo aumento das situações que passam a ficar sujeitas apenas ao licenciamento ambiental simplificado). Espera-se que as discussões apresentadas possam contribuir para o debate quanto às modificações do LA, de forma que as ações e mudanças legais propostas estejam em conformidade com os objetivos da AIA e do LA e que a proteção ambiental seja garantida.

Palavras-chave: simplificação; avaliação de impacto ambiental; legislação. 
ABSTRACT: Despite the importance of Environmental Impact Assessment (EIA) and Environmental Licensing (EL) as environmental management instruments, they had been criticized for lack of clarity about their benefits. In this context, the simplification and efficiency of these instruments are recurrently topics of interest. In Brazil, federal law proposals are under discussion and there have been initiatives of streamlining these instruments in various states. That is the case of the state of Minas Gerais, where changes in the legal norms that regulate EIA and EL were made between 2016 and 2018. In this paper those changes were analyzed, aiming to identify potential benefits and harms when trying to accomplish EIA and EL objectives. Modifications in legal norms were identified based on documental analysis of current and former legal norms that regulate EIA and EL in Minas Gerais, which were latter evaluated against EIA best practices presented in literature. It was identified that modifications occurred virtually in every phase of EL and EIA processes. Some of them represent important improvements (use of digital and online resources, inclusion of locational criteria in screening, modification of parameters to define dimension of activities and creation of a monitoring and inspection center), while others need to be observed more carefully (dismissal of the Operation License renew for some activities, reduction on the participation of COPAM in decision making, and significant increase of cases that are subject only of simplified environmental license). We hope that the discussion presented can contribute to the debate regarding LA modifications, so that proposed actions and law alterations are in line with EIA and EL objectives and environmental protection can be guaranteed.

Keywords: streamlining; environmental impact assessment; law.

\section{Introdução}

A Avaliação de Impacto Ambiental (AIA) é o "processo de identificação, previsão, avaliação e mitigação dos efeitos relevantes - biofísicos, sociais e outros - de propostas de desenvolvimento antes de decisões fundamentais serem tomadas e de compromissos serem assumidos" (IAIA, 1999). A AIA tem sido mundialmente utilizada (Morgan, 2012), inclusive pelo Brasil, onde foi definida como um dos instrumentos da Política Nacional de Meio Ambiente - PNMA (Brasil, 1981).

Do modo como foi regulamentada no país, a AIA está associada ao Licenciamento Ambiental (LA) - outro instrumento da PNMA (Brasil, 1981). Neste contexto, o LA é definido como o "procedimento administrativo pelo qual o órgão ambiental competente licencia a localização, instalação, ampliação e a operação de empreendimentos e atividades utilizadoras de recursos ambientais, consideradas efetiva ou potencialmente poluidoras ou daquelas que, sob qualquer forma, possam causar degradação ambiental" (CONAMA, 1997), sendo que, para os casos de empreendimentos com potencial de causar significativo impacto ambiental, a AIA fornece suporte para a análise das solicitações da licença ambiental (Almeida \& Montaño, 2015). A competência para a realização do LA no Brasil é federal, estadual ou municipal (Brasil, 2011), sendo que cabe ao órgão competente definir procedimentos específicos (CONAMA, 1997).

Apesar do reconhecimento da AIA como um importante instrumento de gestão ambiental, ela ainda recebe muitas críticas, principalmente porque seus benefícios nem sempre são claros (Morrison-Saunders et al., 2015). Neste contexto, a simplificação e a eficiência da AIA têm sido preocupações recorrentes entre seus praticantes e pesquisadores (Lawrence, 2013; Pope et al., 2013) e tal fenômeno é particularmente claro no Brasil (Fonseca et al., 2017). 
Diante deste cenário de buscar melhorias para a AIA no Brasil, ainda que sob diferentes interesses, diversos atores têm formulado propostas para modificações no sistema de AIA e LA, como, por exemplo, a Associação Brasileira de Entidades Estaduais de Meio Ambiente (ABEMA, 2013), a Confederação Nacional da Indústria (CNI, 2013) e o Fórum de Meio Ambiente do Setor Elétrico (FMASE, 2013) (Fonseca et al., 2017).

Além disso, projetos de lei têm tramitado no cenário nacional e, conforme Bragagnolo et al. (2017), tratam de propostas preocupantes para a proteção ambiental. Ainda, no âmbito dos estados, iniciativas de simplificação dos sistemas de AIA e LA já têm sido adotadas (e.g. Fonseca \& Rodrigues, 2017), o que é um fator importante para o instrumento, visto que boa parte dos processos de licenciamento ocorre em nível estadual.

Minas Gerais (MG) foi um dos estados pioneiros no uso daAIAe do LA(Almeida, 2013) e é também um dos estados que promoveu mudanças nas normas legais entre 2016 e 2018. Dentre essas mudanças destaca-se a publicação da Deliberação Normativa do Conselho Estadual de Política Ambiental (DN COPAM) 217/217, que revogou, dentre outras, a DN COPAM 74/2004. De acordo com a Secretaria Estadual de Meio Ambiente e de Desenvolvimento Sustentável, a nova DN teve como objetivo promover a modernização e racionalização dos processos de LA (SEMAD, 2018a).

As críticas e as modificações ao sistema de LA e AIA, porém, mesmo sendo necessárias, precisam ser vistas com cautela, em especial no que tange aos seus efeitos sobre a proteção ambiental, visto que, como sugerem Pope et al. (2013), as reformas nos sistemas tornaram-se uma das principais ameaças à eficácia destes instrumentos. Avaliar essas reformas, então, é relevante para as pesquisas na área.
Neste contexto, este artigo tem como objetivo analisar as mudanças recentes nas normas legais que regem o sistema de LA e AIA no estado de MG, frente às boas práticas, possibilitando inferir sobre potenciais benefícios ou prejuízos delas decorrentes para o cumprimento dos objetivos dos instrumentos e para a proteção ambiental.

\section{Metodologia}

A pesquisa consistiu na análise documental das normas legais, atuais e antigas, que tratam do sistema de Licenciamento Ambiental no âmbito do estado de MG, levantando as modificações e discutindo-as frente às boas práticas internacionais da AIA presentes em documentos técnicos da área e artigos científicos. Para melhor descrição do sistema de licenciamento com AIA, o processo foi dividido nas etapas propostas por Sánchez (2013): apresentação da proposta, triagem, escopo, elaboração dos estudos, participação, análise técnica, decisão e monitoramento. Também foi levado em consideração o proposto por Almeida \& Montaño (2017), que, a partir da relação brasileira entre AIA e LA, compreendem que o licenciamento é um elemento integrante do sistema de AIA. Assim, ao considerar as etapas da AIA propostas por Sánchez (2013), também se contempla o ciclo do LA (suas diferentes licenças) e a renovação da licença presente nas etapas pós-aprovação (acompanhamento e monitoramento).

$\mathrm{O}$ antigo funcionamento do sistema foi descrito com base na DN COPAM 12/1994, DN COPAM 74/2004, Resolução SEMAD 390/2005 e Decreto Estadual 44.844/2008. Para auxiliar nesta descrição foi utilizado o trabalho de Almeida \& Montaño 
(2015). O sistema atual foi descrito com base na Lei Estadual 21.972/2016, nos Decretos Estaduais 47.042/2016, 47.137/2017 e 47.383/2018 e nas DNs COPAM 217/2017 e 225/2018. Ainda, foram usadas as informações disponíveis no sítio eletrônico do órgão ambiental mineiro, consultado entre janeiro e março de 2019 e disponível em http://www. meioambiente.mg.gov.br/regularizacao-ambiental. Como também ocorreram mudanças importantes no que diz respeito ao licenciamento ambiental municipal, foi realizada uma descrição da alteração da DN COPAM 102/2006 para as DNs COPAM 213/2017 e 219/2018. Uma linha do tempo das legislações avaliadas é apresentada na Figura 1.

Com relação às boas práticas usadas para a discussão sobre os avanços e retrocessos da legislação analisada, estas foram baseadas em revisão da literatura e apoiadas nos princípios internacionalmente disseminados para o instrumento, principalmente pela International Association for Impact Assessment (Associação Internacional para a Avaliação de Impactos), que busca sintetizar as diferentes visões dos atores envolvidos no processo.

\section{3. $O$ antes e depois das modificações das normas legais}

Na sequência, o sistema de LA é descrito de acordo com as normas legais antigas e atuais para cada uma das etapas de AIA propostas por Sánchez (2013).

Apresentação da proposta: Em MG, o processo de LA, tanto no sistema antigo quanto no atual, tem início com o recebimento da solicitação de licenciamento enviado pelo empreendedor/consultoria, mediante o preenchimento do Formulário

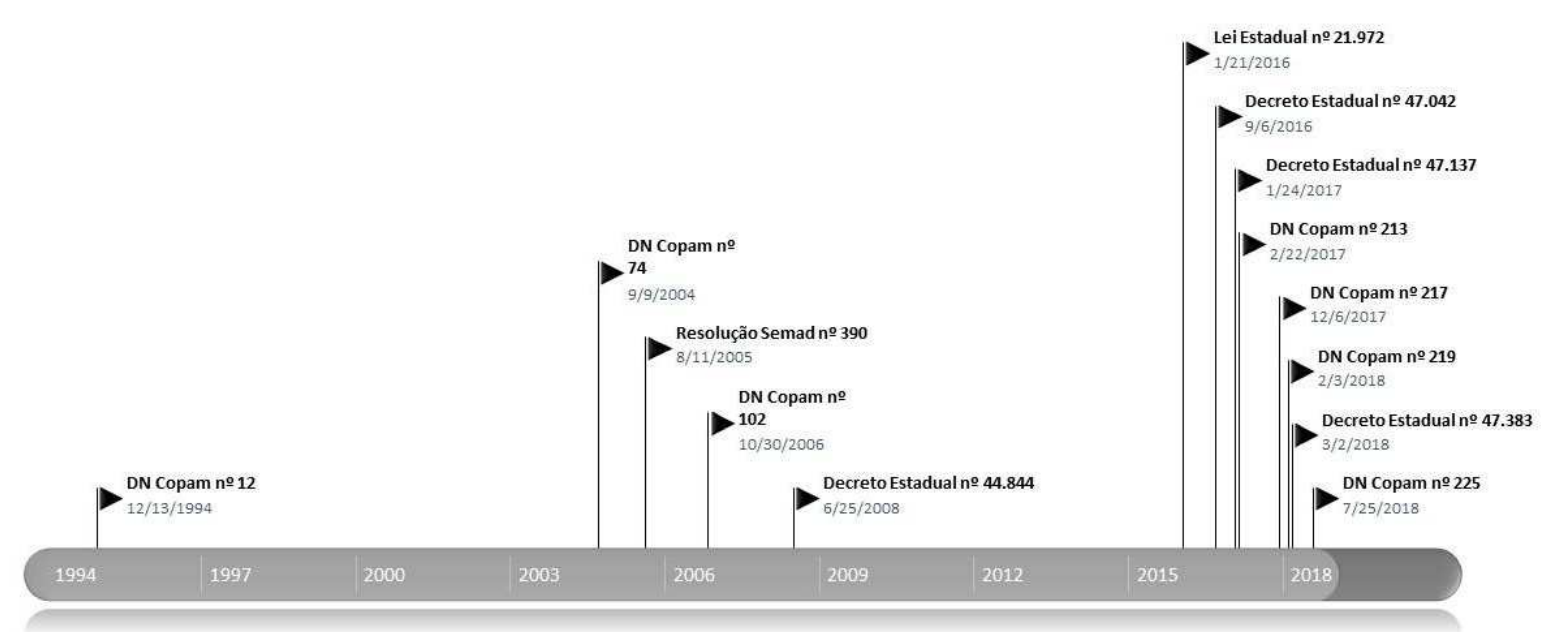

FIGURA 1 - Evolução da legislação ambiental mineira analisada neste trabalho. 
de Caracterização do Empreendimento (FCE), contendo informações relacionadas, principalmente, com o porte e a localização do empreendimento proposto (Almeida \& Montaño, 2015; SEMAD, 2018b; 2019a). No sistema atual, porém, foi criado o 'Sistema de Requerimento de Licenciamento Ambiental' ${ }^{1}$, onde o início do processo de LA e a emissão da Certidão de Dispensa são realizados de forma eletrônica e online.

Na página online deste sistema, também são disponibilizados manuais de orientação, um arquivo simulador - que possibilita realizar processo de triagem, indicando o enquadramento e modalidade de LA a que o empreendimento estará sujeito, favorecendo o planejamento da regularização ambiental pelo empreendedor -, o FCE eletrônico e a Infraestrutura de Dados Espaciais do Sistema Estadual de Meio Ambiente e Recursos Hídricos (IDE-SISEMA), que permite acesso a dados e informações ambientais georreferenciados necessários para o preenchimento do FCE (SEMAD, 2018b). No novo sistema, o IDE-SISEMA também será disponibilizado como um instrumento de análise técnica dos processos de licenciamento ambiental (COPAM, 2017). O empreendedor, então, é instruído a consultar o IDE-SISEMA para verificar a incidência dos critérios locacionais e dos fatores de restrição e de vedação, preencher o FCE eletrônico e enviá-lo à Secretaria de Meio Ambiental e Desenvolvimento Sustentável (SEMAD) por meio do sistema online (SEMAD, 2018b).

Triagem: No processo de triagem, um primeiro passo trata de identificar se a atividade está sujeita ao Licenciamento Ambiental. No sistema antigo, segundo Almeida \& Montaño (2015), partia-se da lista apresentada no Anexo 1 da Resolução CONAMA
237/1997. Para atividades não listadas, o empreendedor deveria solicitar a Certidão de Dispensa. Já para as atividades listadas e desde que não houvesse outra norma que o dispensasse do LA, o empreendimento seria classificado em uma das 6 classes definidas pela DN COPAM 74/2004, de acordo com seu porte e potencial poluidor/degradador (COPAM, 2004).

$O$ potencial poluidor/degradador geral da atividade, considerado característica intrínseca à tipologia da atividade (Almeida \& Montãno, 2015), era dividido em pequeno, médio ou grande, sendo obtido a partir da potencial interferência da atividade no solo, ar e água (COPAM, 2004). Quanto ao porte da atividade, também era dividido em pequeno, médio ou grande, de acordo com algum quesito de 'tamanho', por exemplo, produção bruta, produção nominal, volume de matéria-prima processada, área útil, capacidade instalada, número de empregados (COPAM, 2004; Almeida \& Montãno, 2015).

Assim, a partir das informações do empreendimento apresentadas no FCE e seguindo as listagens de tipologias e respectivas definições de potencial poluidor/degradador e porte constantes nos anexos da DN COPAM 74/2004, a atividade deveria ser enquadrada segundo seu potencial poluidor/degradador e seu porte e, na sequência, utilizava-se a Tabela A-1 da DN COPAM 74/2004 (Tabela 1) que, a partir do cruzamento de ambas as características, determinava a classe do empreendimento (1 a 6).

Para os empreendimentos classe 1 ou 2, o processo seria instruído com base na Autorização Ambiental de Funcionamento (AAF), processo bastante simplificado e de natureza declaratória (Rocha \& Fonseca, 2014; Almeida \& Montãno, 2015). Nestes casos, um dos documentos que integravam

\footnotetext{
${ }^{1}$ Disponível em http://licenciamento.meioambiente.mg.gov.br/site/index. Acesso em: 06/02/2019.
} 
o processo era o Termo de Responsabilidade, por meio do qual o responsável legal pelo empreendimento se comprometia a instalar/operar seu empreendimento dentro das normas e padrões ambientais vigentes, mas não havia qualquer tipo de análise técnica, vistoria ou inspeção prévia, tampouco era previsto o envolvimento do COPAM (Almeida \& Montãno, 2015). Já os de classes de 3 a 6 estavam sujeitos ao licenciamento apoiado em AIA, existindo a necessidade da elaboração de estudos ambientais (Almeida \& Montãno, 2015) e sendo composto por três fases - prévia, instalação e operação (COPAM, 2004). Para empreendimentos classes 3 e 4, porém, havia a possibilidade da emissão da Licença Prévia (LP) concomitante com a Licença de Instalação (LI).

No sistema atual, a norma legal que orienta o processo de triagem é a DN COPAM 217/2017 (que revogou a DN COPAM 74/2004 e suas alterações) que, em seu artigo $10^{\circ}$, dispensa do licenciamento ambiental no âmbito estadual as atividades e em- preendimentos não listados nesta DN (COPAM, 2017). Assim, apesar de o sistema de LA continuar observando a Resolução CONAMA 237/1997, a nova DN evidencia os casos em que o LA é dispensado. Para as atividades listadas, deve-se realizar o seu enquadramento a partir da relação entre seu potencial poluidor/degradador, porte e localização (COPAM, 2017). Para isso, de modo semelhante à DN COPAM 74/2004, a DN de 2017 traz em seu anexo único a listagem de atividades, apresentando seu enquadramento em termos de potencial poluidor/ degradador e os parâmetros para enquadramento de porte. A conjugação desses dois fatores a partir da Tabela 2 do Anexo Único da DN COPAM 217/2017 (Tabela 2) possibilita a fixação da classe da atividade, podendo ser de 1 a 6 .

$\mathrm{Na} \mathrm{DN}$ em vigor, porém, houve alterações com relação ao conteúdo das listagens de atividades, ocorrendo exclusão, unificação e inclusão de atividades, alterações dos códigos, mudança da

TABELA 1 - Critérios de classificação da atividade segundo a DN COPAM 74/2004.

\begin{tabular}{lcccc} 
& & \multicolumn{3}{c}{ Potencial poluidor/degradador geral da atividade } \\
\cline { 3 - 5 } & & P & M & G \\
\cline { 3 - 5 } Porte do empreendimento & P & 1 & 1 & 3 \\
& M & 2 & 3 & 5 \\
& G & 4 & 5 & 6 \\
\hline
\end{tabular}

FONTE: COPAM (2004).

TABELA 2 - Critérios de classificação da atividade segundo a DN COPAM 217/2017.

\begin{tabular}{lllll} 
& & \multicolumn{3}{c}{ Potencial poluidor/degradador geral da atividade } \\
\cline { 3 - 5 } & & P & M & G \\
\cline { 3 - 5 } Porte do empreendimento & P & 1 & 2 & 4 \\
& M & 1 & 3 & 5 \\
& G & 1 & 4 & 6 \\
\hline
\end{tabular}

FONTE: COPAM (2017). 
atividade para outra listagem, alterações no potencial poluidor e alterações nos critérios de porte ou em sua redação. A Tabela 3 apresenta exemplos de algumas das alterações nas listagens.

Nesta nova forma de classificar o empreendimento, o potencial poluidor/degradador da atividade passou a ter maior peso. Desse modo, atividades com pequeno potencial poluidor/degradador, ainda que de grande porte, passam a ser enquadradas em classes menores, ao passo que atividades com potencial poluidor/degradador maior, mesmo que de pequeno porte, passam a enquadrar em classes maiores. A Tabela 4 reúne os resultados do enquadramento nas duas DNs, evidenciando as alterações resultantes.

Além do enquadramento da atividade nas classes de 1 a 6 , no novo sistema também é usado um fator locacional para o estabelecimento da modalidade de licenciamento a ser seguida. Este fator locacional diz respeito à relevância e à sensibilidade

TABELA 3 - Exemplos de alterações nas listagens das atividades sujeitas ao Licenciamento em Minas Gerais, considerando as DNs COPAM $74 / 2004$ e $217 / 2017$.

\begin{tabular}{cl}
\hline Alteração & Exemplos \\
\hline Exclusão & $\begin{array}{l}\text { Atividade "obras de infraestrutura (pátios de resíduos produtos e oficinas)" (A-05-02-9), da listagem de atividades } \\
\text { de mineração. }\end{array}$ \\
\hline Unificação & $\begin{array}{l}\text { Atividade "fabricação de papelão" (C-01-04-1) unificada com a atividade "fabricação de papelão, papel, cartolina, } \\
\text { cartão e polpa moldada, utilizando celulose e/ou papel reciclado como matéria-prima" (C-01-03-1). }\end{array}$ \\
\hline Inclusão & Atividade "reciclagem de eletroeletrônicos contendo resíduos perigosos classe I" (F-05-10-7). \\
\hline $\begin{array}{c}\text { Alteração do po- } \\
\text { tencial poluidor }\end{array}$ & $\begin{array}{l}\text { Diminuição do potencial poluidor da atividade "extração de água mineral ou potável de mesa" (A-04-01-4) de médio } \\
\text { para pequeno; diminuição do potencial poluidor da atividade "portos fluviais" (E-01-06-6) de grande para médio; } \\
\text { diminuição do potencial poluidor da atividade "transporte rodoviário de resíduos perigosos - classe I" (F-02-01-1) de } \\
\text { grande para pequeno. }\end{array}$ \\
\hline
\end{tabular}

Alteração dos critérios de porte
Exclusão do parâmetro " $n^{\circ}$ de empregados", anteriormente utilizado em conjunto com o parâmetro "área útil” para atividades como "fabricação de tintas, esmaltes, lacas, vernizes impermeabilizantes, solventes e secantes" (C-04-15-4) e "terminal minerário" (E-01-14-7); aumento dos limites de porte, para as atividades "barragem de saneamento" (E-0301-8) e "tratamento químico para preservação de madeira" (B-10-07-0, na DN 217/2017); diminuição dos limites de porte para a atividade "extração de areia e cascalho para utilização imediata na construção civil" (A-03-01-8).

TABELA 4 - Enquadramento das atividades de acordo com as DNs COPAM 74/2004 e 217/2017.

\begin{tabular}{ccccccccccc}
\hline & $\mathbf{P}+\mathbf{P}$ & $\mathbf{P}+\mathbf{M}$ & $\mathbf{P}+\mathbf{G}$ & $\mathbf{M}+\mathbf{P}$ & $\mathbf{M}+\mathbf{M}$ & $\mathbf{M}+\mathbf{G}$ & $\mathbf{G}+\mathbf{P}$ & $\mathbf{G}+\mathbf{M}$ & $\mathbf{G}+\mathbf{G}$ \\
\hline DN COPAM 74/2004 & Classe1 & Classe 2 & Classe 4 & Classe 1 & Classe 3 & Classe 5 & $\begin{array}{c}\text { Classe } \\
3\end{array}$ & $\begin{array}{c}\text { Classe } \\
5\end{array}$ & $\begin{array}{c}\text { Classe } \\
6\end{array}$ \\
\hline DN COPAM 217/2017 & Classe 1 & Classe 1 & Classe 1 & Classe 2 & Classe 3 & Classe4 & $\begin{array}{c}\text { Classe } \\
4\end{array}$ & $\begin{array}{c}\text { Classe } \\
5\end{array}$ & $\begin{array}{c}\text { Classe } \\
6\end{array}$ \\
\hline
\end{tabular}

Legenda: $1^{\circ}$ termo $+2^{\circ}$ termo, sendo $1^{\circ}$ termo o referente ao potencial poluidor/degradador da atividade e o $2^{\circ}$ termo ao porte. 
dos componentes ambientais do local proposto para a realização da atividade objeto do licenciamento e pode receber peso 1 ou 2, conforme especificado na Tabela 4 do Anexo Único da DN COPAM 217/2017, ou peso 0 , caso não se enquadre em nenhuma das situações definidas nesta tabela (COPAM, 2017). Além dos critérios locacionais, também foram definidos fatores de restrição e vedação, que devem ser considerados nos estudos ambientais que irão compor o processo de LA, mas não interferem no enquadramento dos empreendimentos (COPAM, 2017). Feito o enquadramento, a classe da atividade e o critério locacional são conjugados a partir da Tabela 3 do Anexo Único da DN COPAM 217/2017 (Tabela 5), fixando-se a modalidade de LA, que podem ser: Licenciamento Ambiental Trifásico (LAT), Licenciamento Ambiental Concomitante (LAC) e Licenciamento Ambiental Simplificado (LAS) (Minas Gerais, 2016a; COPAM, 2017; Minas Gerais, 2018).

Neste contexto, a AAF foi extinta (Lei Estadual 21.972/2016), dando lugar à Licença Ambiental Simplificada (LAS), obtida por meio do Licenciamento Ambiental Simplificado, realizado em uma única etapa mediante o preenchimento de informações a respeito da atividade em cadastro eletrônico (LAS/Cadastro) ou mediante a entrega de Relatório Ambiental Simplificado (LAS/RAS) (Minas Gerais, 2016a; COPAM, 2017). O LAS/Cadastro é autodeclaratório, sendo a Licença emitida eletronicamente sem qualquer tipo de análise técnica. No caso de LAS/RAS, há a análise técnica das informações de caracterização do empreendimento e de controle ambiental. Em ambos os casos, porém, não ocorre análise de viabilidade ambiental e o processo não é apoiado em AIA.

O LAT transcorre similarmente ao licenciamento federal estipulado pela Resolução CONAMA 237/1997, sendo analisadas as etapas de viabilidade ambiental, instalação e operação da atividade e com LP, LI e LO expedidas separadamente (Minas Gerais, 2016a). Já o LAC envolve a análise das mesmas três etapas previstas no LAT, porém, com a expedição de duas ou mais licenças concomitantemente, podendo ocorrer de duas maneiras distintas. O primeiro caso é o chamado LAC1, no qual a análise das etapas de LP, LI e LO ocorrem em uma única fase. O segundo caso é o LAC2, com a análise das LPe LI em uma única fase e, posteriormente, a LO; ou com análise da LP e, na sequência, da LI e LO concomitante (Minas Gerais, 2018). A Figura 1 exibe as modalidades do LA no sistema atual.

O processo de triagem, tanto antes como após a mudança legal, culmina com a emissão, pelo Sistema Integrado de Informação Ambiental (SIAM), do Formulário de Orientação Básica (FOB), que apresenta qual a classe em que o empreendimento foi enquadrado, a modalidade de LA requerida, o estudo ambiental e outros documentos necessários à formalização do processo (Almeida \& Montaño, 2015; COPAM, 2017).

TABELA 5 - Modalidades de licenciamento de acordo com a DN Copam nº 217/2017.

\begin{tabular}{cccccccc}
\cline { 2 - 7 } & \multicolumn{7}{c}{ Classe por porte e potencial poluidor/degradador } \\
\cline { 2 - 7 } Critério locacional & $\mathbf{1}$ & $\mathbf{2}$ & $\mathbf{3}$ & $\mathbf{4}$ & $\mathbf{5}$ & $\mathbf{6}$ \\
& $\mathbf{1}$ & LAS/Cadastro & LAS/Cadastro & LAS/RAS & LAC1 & LAC2 & LAC2 \\
& $\mathbf{2}$ & LAS/RAS & LAS/RAS & LAC1 & LAC2 & LAC2 & LAT \\
& & & LAC1 & LAC2 & LAC2 & LAT & LAT \\
\hline
\end{tabular}

FONTE: COPAM (2017). 


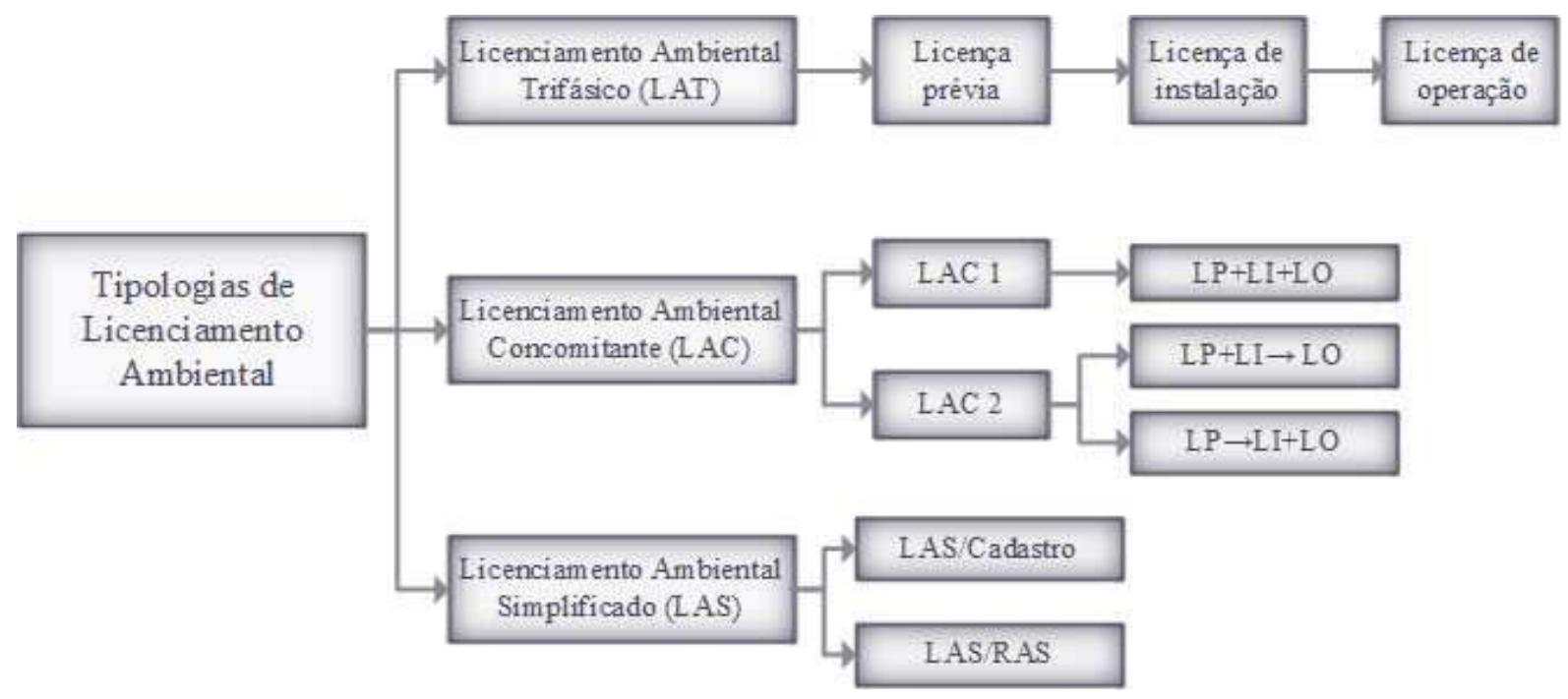

FIGURA 2 - Modalidades do Licenciamento Ambiental à luz da DN Copam nº 217/2017.

FONTE: elaborada a partir de COPAM (2017).

No sistema atual, no qual o Formulário de Caracterização do Empreendimento (FCE) é eletrônico, uma triagem prévia é feita de maneira automática pelo próprio formulário, que também gera orientações para a formalização do processo. Para os casos de LAS/Cadastro, as orientações emitidas são definitivas. Para os demais casos, o FOB com as orientações definitivas é emitido posteriormente pelo SIAM e enviado ao empreendedor (SEMAD, 2019a).

Com relação aos estudos ambientais, no sistema antigo podiam ser solicitados o Estudo de Impacto Ambiental e respectivo Relatório de Impacto Ambiental (EIA/RIMA) ou o Relatório de Controle Ambiental (RCA), solicitado quando da dispensa do EIA. Como descrito por Almeida \& Montaño (2015), a solicitação de EIA/RIMA era definida com base no Art. $2^{\circ}$ da Resolução CONAMA n ${ }^{\circ}$ 001/1986 e de acordo com a discricionariedade do órgão ambiental, considerando a localização e características do empreendimento, caso a caso. No sistema atual, os estudos continuam sendo os mesmos (COPAM, 2017) e também não fica claro em que situações ou a partir de quais critérios a dispensa do EIA poderá se dar, indicando que essa decisão continua sendo baseada na discricionariedade do órgão ambiental.

Escopo e elaboração dos estudos: Não houve mudanças na definição do escopo dos estudos. Tanto nos casos de EIA/RIMA como de RCA, o escopo é definido por Termos de Referência (TR) pré-existentes (Almeida \& Montaño, 2015). No sítio eletrônico da SEMAD é disponibilizado o TR geral e alguns TRs específicos para determinadas 
atividades, como agrossilvopastoris, minerárias, indústria química e parcelamento do solo (SEMAD, 2019b). Portanto, o escopo continua sendo baseado em TRs já prontos, específicos apenas para algumas tipologias de empreendimentos.

No entanto, no que tange à elaboração dos estudos, é importante destacar que a DN COPAM 217/2017, diferentemente das normas anteriores, tem uma seção específica para listar os tipos de estudos ambientais e suas funções (Seção III - Dos Estudos Ambientais) (COPAM, 2017). Ainda, a referida deliberação pede que os estudos ambientais devem considerar em sua abordagem os fatores de restrição ou vedação apresentados no seu Anexo Único (COPAM, 2017). Uma vez verificado qual o TR que se aplica ao caso do empreendimento em licenciamento, o estudo deve ser elaborado. Vale destacar que o EIA/RIMA deve ser realizado por equipe multidisciplinar habilitada (CONAMA, 1986).

Também se passou a exigir, como medidas de controle ambiental determinadas para o licenciamento de atividade que possa colocar em grave risco vidas humanas ou o meio ambiente, a elaboração e implementação de Plano de Ação de Emergência, Plano de Contingência e Plano de Comunicação de Risco, sendo que o Plano de Ação de Emergência deve incluir sistema de alerta sonoro ou outra solução tecnológica de maior eficiência (Minas Gerais, 2016a).

Análise técnica: Uma vez elaborados e protocolados os estudos e documentos solicitados, o processo entra em fase de análise pelo órgão ambiental. Inicialmente, o estudo é submetido a uma verificação do cumprimento do TR e, em seguida, tal conteúdo é analisado em relação aos aspectos metodológicos empregados nos levantamentos realizados e na avaliação dos impactos ambientais, procurando-se verificar, sobretudo, se as informações apresentadas são suficientes para orientar a tomada de decisão (Almeida \& Montãno, 2015). Ainda segundo os referidos autores, durante esta etapa são realizadas vistorias ao local do futuro empreendimento, de modo a auxiliar a análise da equipe técnica responsável (formada por profissionais de diversas áreas). Se as informações apresentadas forem insuficientes, informações complementares (IC) podem ser solicitadas. Nos casos de empreendimentos de maior complexidade, são realizadas reuniões multidisciplinares para a avaliação do estudo e, em alguns casos, são envolvidas outras entidades na análise técnica, por exemplo, órgãos gestores de Unidades de Conservação, Comitê de Bacias, entre outros (Almeida \& Montaño, 2015). Este procedimento não sofreu alterações. No entanto, as novas normas regem que o órgão ambiental pode fazer apenas um pedido de IC, exceto nos casos de fatos supervenientes devidamente justificados (COPAM, 2017).

$\mathrm{Na}$ legislação antiga, a competência para realizar a análise técnica nos processos era da SEMAD por meio das Superintendências Regionais de Meio Ambiente e Desenvolvimento Sustentável (SUPRAMs). Atualmente, as SUPRAMs continuam tendo essa competência, mas, para o caso de "projetos prioritários", a análise será feita pela Superintendência de Projetos Prioritários (SUPRI). A SUPRI compõe a estrutura complementar da SEMAD (Minas Gerais, 2016a; Minas Gerais, 2016b), cabendo-lhe analisar os projetos considerados prioritários "em razão da relevância da atividade ou do empreendimento para a proteção ou reabilitação do meio ambiente ou para o desenvolvimento social e econômico do Estado" (Minas Gerais, 2016a). 
A classificação como "projeto prioritário" cabe à SEMAD quando se trata de empreendimento público (Minas Gerais, 2016a) e, quando se trata de empreendimento privado, cabe ao grupo de coordenação de políticas públicas setoriais (Minas Gerais, 2016e), composto por Secretários de Estado (Minas Gerais, 2016d).

Quanto ao prazo de análise do órgão ambiental, este continua sendo de 6 meses, exceto em casos instruídos por EIA/RIMA ou quando ocorrer audiência pública, casos em que o prazo é estendido para 12 meses; entretanto, como novidade, uma vez esgotados estes prazos "sem que o órgão ambiental competente tenha se pronunciado, os processos de licenciamento ambiental serão incluídos na pauta de discussão e julgamento da unidade competente do Copam, sobrestando-se a deliberação quanto aos demais assuntos" (Minas Gerais, 2016a).

Participação da sociedade: A participação pública durante o processo de LA apoiado em AIA é prevista, tanto no sistema antigo quanto no atual, em dois formatos: por meio de audiência pública a ser realizada durante a análise e tramitação do EIA e previamente à elaboração do Parecer Único e deliberação sobre o requerimento da LA (COPAM, 1994; Almeida \& Montaño, 2015; COPAM, 2018); e por meio da participação da sociedade civil na composição do Conselho Estadual de Política Ambiental (COPAM), que tem papel na tomada de decisão (Minas Gerais, 2016c).

Com relação à audiência pública, os procedimentos para sua realização eram definidos pela DN COPAM 12/1994 que, dentre outras coisas, definia que para os casos de EIA/RIMA a audiência poderia ser solicitada pelo próprio órgão ambiental, COPAM, Poder Público Estadual ou Municipal, Ministério Público, entidade civil ou grupo de 50 ou mais cidadãos, conforme prazo para manifestação definido em edital pelo COPAM (COPAM, 1994). Regras para se dar publicidade à audiência e as regras para sua organização também eram definidas pela DN COPAM 12/1994.

No sistema atual, a DN COPAM 12/1994 foi substituída pela DN COPAM 225/2018. Na nova norma legal, foram alterados os solicitantes da audiência (prefeito do município sede ou prefeito de município sujeito aos potenciais impactos ambientais da atividade ou empreendimento; Ministério Público; o próprio empreendedor; entidade civil sem fins lucrativos e que tenha por finalidade social a defesa de interesse econômico, social, cultural ou ambiental; e grupo de 50 ou mais cidadãos). Ainda, a organização da audiência sofreu algumas alterações, por exemplo, o tempo destinado à apresentação do empreendedor - que passou de 40 para 45 minutos, o detalhamento do conteúdo mínimo a ser abordado pelo empreendedor em sua apresentação e a organização das manifestações do público e respostas do empreendedor de maneira intercalada (COPAM, 2018). Outra alteração importante é a inclusão dos meios digitais e da rede mundial de computadores para a divulgação das informações relacionadas à solicitação e realização da audiência, bem como para disponibilização do RIMA e transmissão online e em tempo real da audiência (COPAM, 2018). Continua-se, no entanto, prevendo a participação pública apenas após a elaboração dos estudos ambientais.

Decisão: No sistema antigo, a decisão sobre o LA de atividades classes 1 e 2 era de competência da SEMAD por meio das SUPRAMs. Já as decisões sobre a viabilidade ambiental do empreendimento, ou seja, decisões no âmbito do LA apoiado em AIA (empreendimentos de classe de 3 a 6) eram 
tomadas pelas Unidades Regionais Colegiadas (URC) do COPAM (Almeida \& Montaño, 2015). Porém, a partir da Lei Estadual 21.972/2016 e dos Decretos Estaduais 47.042/2016 e 47.383/2018, a competência de decidir sobre o processo de Licenciamento Ambiental passou a ser definida com base nas seguintes regras (Minas Gerais, 2016c; Minas Gerais, 2018):

i. é competência da SEMAD, por meio das SUPRAMs ou da SUPRI, a decisão sobre as atividades: de pequeno porte e pequeno potencial poluidor (classe 1), de pequeno porte e médio potencial poluidor (classe 2), de médio porte e pequeno potencial poluidor (classe 1), de pequeno porte e grande potencial poluidor (classe 4), de médio porte e médio potencial poluidor (classe 3 ) e de grande porte e pequeno potencial poluidor (classe 1);

ii. é competência do COPAM, por meio de suas Câmaras Técnicas, a decisão sobre as atividades: de médio porte e grande potencial poluidor (classe 5), de grande porte e médio potencial poluidor (classe 4 ) e de grande porte e grande potencial poluidor (classe 6).

Também será de competência do COPAM a decisão sobre processo de licenciamento ambiental quando o órgão ambiental competente não se pronunciar dentro dos prazos definidos pela legislação (Minas Gerais, 2016a).

No caso de aprovação do empreendimento, a LP é emitida. Dando sequência às etapas do LA, para a emissão da LI são requeridos o cumprimento das condicionantes e exigências da LP e a apresentação do Plano de Controle Ambiental (PCA), que deve conter "as propostas para prevenir, eliminar, mitigar, corrigir ou compensar os impactos ambientais detectados por meio do RCA ou do EIA" (COPAM, 2017). Atendidas as condicionantes e construído o empreendimento segundo as exigências das licenças anteriores, a LO pode ser solicitada e sua expedição autoriza que o empreendimento entre em funcionamento. As decisões da emissão da LI e LO também são tomadas conforme as regras já mencionadas.

Monitoramento: Na etapa de pós-aprovação, tanto no sistema antigo quando no atual, a SUPRAM realiza o acompanhamento do cumprimento das condicionantes e dos programas de monitoramento da atividade por meio do Relatório de Avaliação do Desempenho Ambiental (RADA), que é o estudo ambiental que dá suporte para a análise das solicitações de renovação da LO (Almeida \& Montaño, 2015; COPAM, 2017). No entanto, a DN COPAM 217/2017 estabelece onze atividades que ficam dispensadas da renovação da LO, dentre elas as de infraestruturas de transporte, linhas de transmissão e energia elétrica, parques cemitérios, parcelamento do solo, barragens de saneamento e de amortecimento de cheias e infraestruturas de irrigação (COPAM, 2017).

Também vale mencionar que, no sistema atual, o prazo de validade da LP, LI e LO foram mantidos (respectivamente cinco, seis e dez anos). Já o prazo de validade da Licença Ambiental Simplificada (LAS) foi definido como igual a 10 anos, ao passo que o prazo de validade da AAF era, no sistema antigo, de quatro anos.

Outra novidade é a criação do Núcleo de Controle Ambiental (NUCAM) pelo Decreto Estadual 47.042/2016, que trata da organização da SEMAD. O NUCAM está ligado à Diretoria de Fiscalização das SUPRAM e tem por objetivos promover o acompanhamento dos sistemas de controle ambiental dos empreendimentos regularizados; aplicar penalidades em decorrência do descumprimento 
da legislação ambiental; atualizar os sistemas informatizados de fiscalização ambiental e autos de infração e acompanhar e verificar o cumprimento de condicionantes estabelecidas pela LO (Minas Gerais, 2016c).

Licenciamento municipal: Em relação ao LA em nível local, entre os anos de 2006 e 2017, vigorava a DN COPAM 102/2006. Esta deliberação estabelecia diretrizes para a cooperação técnica e administrativa entre o estado e os municípios, visando ao licenciamento e fiscalização de empreendimentos de impacto local, além da interação destes municípios com o sistema de outorga do direito de uso das águas e com o sistema de autorização para exploração florestal estaduais. Ela também exigia que os municípios interessados em celebrar convênio possuíssem um sistema municipal de gestão ambiental com: política municipal de meio ambiente; conselho de meio ambiente; órgão técnico-administrativo dotado de técnicos multidisciplinares; sistema de licenciamento e fiscalização ambiental; destinação das receitas geradas pelas ações previstas ao sistema de gestão ambiental municipal; sistema de disposição final de resíduos sólidos e de tratamento de efluentes domésticos; e plano diretor (COPAM, 2006). Assuntos de mesma natureza também eram regulamentados pelo Decreto Estadual 46.937/2016, segundo o qual os municípios que dispunham de determinada estrutura de gestão ambiental podiam celebrar convênio com o estado, visando ao LA de determinadas atividades. Esta estrutura englobava uma política municipal de meio ambiente, um conselho de meio ambiente, um órgão técnico-administrativo dotado de corpo técnico e um sistema de fiscalização ambiental (Minas Gerais, 2016b).
$\mathrm{Na}$ atualidade, as regulamentações a respeito do LA municipal passaram a ser especificadas pela DN COPAM 213/2017 e alterações trazidas pela DN COPAM 219/2018, regulamentando o disposto no art. $9^{\circ}$, inciso XIV, alínea "a" e no art. $18, \S 2^{\circ}$ da Lei Complementar 140/2011, a fim de estipular o que seria impacto local e estabelecer as tipologias de empreendimentos e atividades cujo licenciamento será atribuição dos municípios. Com a nova deliberação, as exigências aos municípios diminuíram, sendo necessários somente órgão ambiental capacitado e conselho municipal de meio ambiente. Outra mudança trazida foi a listagem em seu anexo das atividades passíveis de licenciamento pelo órgão municipal, já especificando com clareza quais atividades teriam impacto local e, portanto, são de competência dos municípios licenciarem, o que era inexistente nas normas legais anteriores (COPAM, 2018).

A Tabela 6 apresenta um resumo das modificações trazidas no sistema de licenciamento ambiental mineiro.

\section{Principais pontos de mudança: avanços e retrocessos}

Um dos avanços do sistema mineiro vem da adoção de procedimentos online tanto na apresentação da proposta, triagem e realização do LAS/ Cadastro como nos mecanismos para propiciar a participação. No primeiro caso, o trâmite online da dispensa de licenciamento e do LAS/Cadastro é uma forma de simplificação do processo, já prevista na Resolução CONAMA 237/1997, e que pode amenizar o acúmulo de processos de licenciamento ambiental à espera de análise técnica, já que uma 
das suas principais causas, segundo Oliveira et al. (2016), é a desproporcionalidade entre o grau de exigência do licenciamento e o potencial de causar impacto dos projetos. Ainda, é necessário considerar que os procedimentos simplificados podem agilizar a concessão de licença e reduzir os custos do processo (Oliveira et al., 2016). Assim, o que é simples deve ser tratado de forma simples e o que é complexo e causador de impacto significativo deve ser analisado de modo mais criterioso. Cabe, então, à triagem balizar o que pode ou não ser licenciado de forma simplificada.

Com relação à participação, considerando que o meio digital, ainda que não garanta a participação, é um espaço importante para sua promoção e para propiciar novos espaços para circulação social (Braga, 2010; Ferreira, 2011), o seu uso para propiciar a participação na AIA é extremamente importante para atender a uma sociedade tecnológica. Os recursos tecnológicos podem, sempre que possível, ser usados para potencializar e ampliar os espaços em que se dialoga e discute os problemas sociais e ambientais (Toth et al., 2012). Assim, as alterações ao ampliar o uso de recursos digitais e online no momento de audiência pública apontam para a ampliação do acesso à participação na AIA.

Já as modificações na etapa de triagem, que talvez sejam as alterações mais importantes no sistema de licenciamento mineiro, merecem ser analisadas com cautela. Inicialmente, a introdução

TABELA 6 - Resumo das principais mudanças ocorridas no processo de licenciamento ambiental e Avaliação de Impacto Ambiental em Minas Gerais.

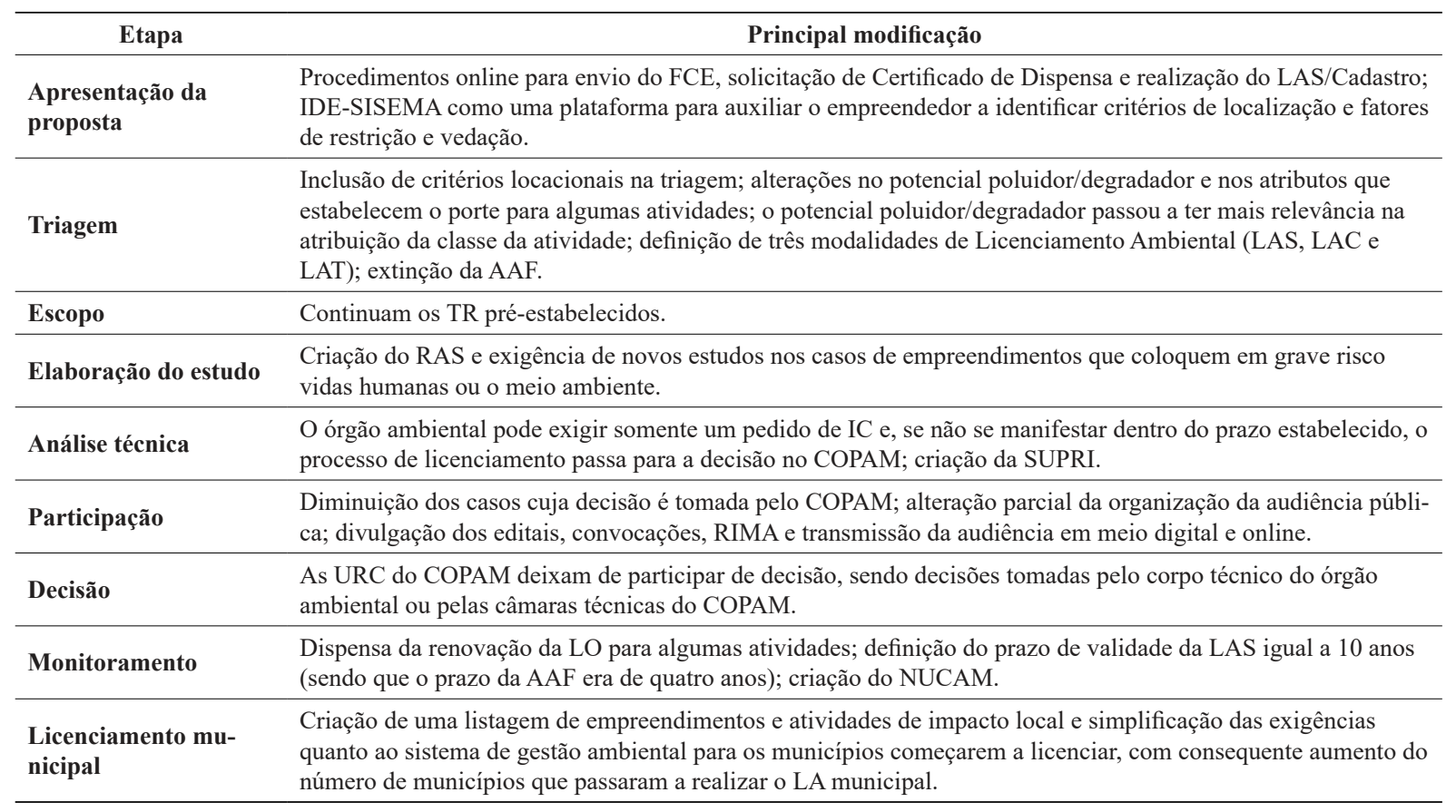


do critério locacional pode ser considerada como grande avanço, pois o potencial de causar impacto de uma atividade depende não somente da pressão que ela exerce sobre o meio (que está associada ao porte e potencial poluidor/degradador da atividade), mas também da sensibilidade ou resiliência do local onde se pretende instalar esta atividade (Sánchez, 2013; Fernandes et al., 2017). Introduzir fatores locacionais nos critérios de triagem foi apontado no trabalho de Fonseca et al. (2017) entre as principais prioridades para a modificação do sistema brasileiro de AIA na opinião de especialistas.

Essa questão em MG não é recente, já tendo sido apresentada em 2011 uma minuta, não aprovada, com propostas de alteração na DN COPAM $74 / 2004$, em que esta levaria em consideração como critério locacional a vulnerabilidade do meio, dada pela carta de Vulnerabilidade Ambiental do Zoneamento Ecológico Econômico do Estado aprovado pela DN COPAM 129/2008 (Almeida \& Montaño, 2015).

Ainda, no trabalho apresentado por Rocha et al. (2016) são relatadas propostas desenvolvidas para o aperfeiçoamento da triagem em Minas Gerais, desenvolvidas no âmbito da "Força-tarefa", instituída em 2015 pelo então Governo de Estado, por meio do Decreto Estadual 46.733/2015.No referido trabalho também é apontada a introdução do quesito locacional à DN COPAM 74/2004, devendo ser considerados nos critérios locacionais áreas geográficas ou componentes ambientais como Unidades de Conservação de proteção integral e uso sustentável, cavidades naturais subterrâneas, corpos d'água classe especial, vegetação nativa, área espeleológica sensível, áreas de preservação permanente, moradores e/ou infraestrutura local, Reserva da Biosfera da Serra do Espinhaço, terras indígenas, Reserva da Biosfera da Mata Atlântica, comunidades quilombolas, Corredor Ecológico Sossego-Caratinga, bens tombados, arqueológicos, registrados e/ou valorados, áreas de conflito por uso de recursos hídricos, áreas ou bens de interesse histórico, artístico, arquitetônico e/ou paisagístico, rios de preservação permanente e áreas de segurança aeroportuária (Rocha et al., 2016).

Assim, as proposições iniciais de considerar a sensibilidade do meio envolviam mais critérios, pensando não somente em áreas já protegidas, conforme adotado pela DN COPAM 217/2017, mas também em demais fatores ambientais com interferência em sua sensibilidade. Logo, cabe questionar se os critérios locacionais usados pela DN COPAM 217/2017 não seriam pouco abrangentes.

As mudanças na triagem mineira incluem, ainda, alterações nos atributos que estabelecem o porte e o potencial poluidor/degradador para algumas atividades e o fato de que o potencial poluidor/ degradador passou a ter mais relevância na atribuição da classe da atividade. Na legislação antiga, eram usados atributos de porte não adequados ao seu propósito, sendo ajustado. Um bom exemplo é o fim do uso do número de empregados como critério de porte, já que diante da automação ou das características da atividade ter mais ou menos empregados não tem relação com a capacidade de causar impacto.

Alterações no potencial poluidor/degradador envolvem tanto casos em que o potencial foi diminuído como aqueles em que foi aumentado. Além deste processo ser guiado por questões técnicas, não é possível ignorar as pressões que alguns setores exercem para a simplificação dos processos de seu interesse, pois, a redução do potencial poluidor pode ter consequências na forma como o LA será 
conduzido. Experiências internacionais indicam que os fatores políticos têm influenciado a prática da AIA (Elliott \& Thomas, 2009) e, segundo Morgan (2012), fatores políticos e econômicos têm sido a força motriz para a simplificação dos sistemas de AIA.

Ademais, a maior relevância dada ao potencial poluidor/degradador na atribuição de classe (vide a Tabela 5) teve implicações especialmente para as atividades cujo potencial poluidor degradador/ degradador se enquadra em pequeno. Explicando melhor: conforme pode ser observado na Tabela 2, uma atividade de pequeno potencial poluidor/ degradador, independe do porte, será sempre enquadrada em classe 1, ficando sempre sujeita ao LAS (LAS/Cadastro ou LAS/RAS, em função do fator locacional, conforme Tabela 5). O LAS/Cadastro é autodeclaratório e o LAS/RAS não representa um processo de licenciamento que envolva uma avaliação de impactos.

Deste modo, embora a DN COPAM 217/2017 explicite em seus artigos 19 e 20 que o licenciamento de algumas atividades, mesmo sendo classes 1 e 2, não podem ser da modalidade LAS/Cadastro (COPAM, 2017), algumas tipologias de empreendimento causadoras de impactos significativos ficam sujeitas apenas ao LAS. É o caso, por exemplo, das usinas eólicas. Mesmo induzindo menores perturbações ao meio ambiente quando comparados a outras formas de energia, os empreendimentos eólicos podem causar significativos impactos, principalmente se instalados em áreas sensíveis e concentrados espacialmente (Aversa, 2018), devendo, portanto, estar sujeitos às modalidades de licenciamento com maior capacidade de avaliar impactos que o LAS. Mais agravante, se a atividade não estiver localizada em UC de proteção integral, área prioritária para conservação ou Sítio Ramsar, será sempre sujeita ao LAS/Cadastro. Ou seja, não estando sujeita a nenhuma análise técnica.

Em resumo, as reduções de potencial poluidor/ degradador e parâmetros de enquadramento de porte associadas à alteração das classes em função da conjugação de potencial poluidor/degradador e porte levaram várias atividades a estarem sujeitas às modalidades de LA mais simples (menor número de LAT e ampliação da aplicação do LAS). Vale destacar que restringir o uso do LAT é uma das propostas que têm sido discutidas para simplificação do sistema de LA no Brasil (ABEMA, 2013; CNI, 2013; Bragagnolo et al., 2017). Modificações similares têm sido observadas também em outros contextos e entendidas como preocupantes por diversos atores (entre eles Bond, et al., 2014; Lawrence, 2013; Pope et al., 2013), demonstrando ser uma questão controversa (Fonseca et al., 2017).

O processo de escopo não sofreu nenhuma modificação, estando os TRs já prontos e disponibilizados na página do órgão ambiental. Existem TRs específicos para algumas atividades e um geral, caso a atividade não seja contemplada com um específico. Almeida \& Montaño (2015) relatam que isso favorece a agilidade do processo, mas impossibilita a análise das especificidades do empreendimento no local pretendido, podendo ocasionar a abordagem de temas irrelevantes e a omissão de aspectos fundamentais na análise de sua viabilidade ambiental, além de não possibilitar nenhuma forma de envolvimento dos diferentes atores. Vale lembrar que o objetivo fundamental do escopo é focar o estudo em questões importantes para a decisão (Kennedy \& Ross, 1992) e generalizar os TR pode acarretar em situação contrária. 
Quanto aos estudos envolvidos no LA com AIA, vale destacar que passou a estar explícito na legislação a exigência de estudos específicos para os casos de empreendimentos que coloquem em grave risco vidas humanas ou o meio ambiente (Minas Gerais, 2016a). Esta alteração foi desencadeada pela tragédia do rompimento da barragem de rejeitos de Fundão, da empresa Samarco, na cidade de Mariana/MG, ocorrida em 05 de novembro de 2015. O caso de Mariana mostrou que a gestão ambiental por parte dos órgãos estatais ainda se encontra bem aquém do necessário, principalmente no que se refere ao Poder de Polícia Ambiental, e isso ocorreria porque as instituições encarregadas da gestão ambiental aparentemente estão tendo suas atividades prejudicadas por insuficiência operacional, o que afeta diretamente a capacidade de monitoramento e fiscalização dos empreendimentos impactantes (César \& Carneiro, 2017).

No entanto, a mudança legal não foi suficiente para evitar novos desastres, já que em 25 de janeiro de 2019 houve o rompimento de uma nova barragem, agora na Mina Córrego do Feijão, da mineradora Vale, situada em Brumadinho, região metropolitana de Belo Horizonte. As leis existem, mas elas precisam ser colocadas em prática aliadas às estratégias de gestão, pois, como apontam Espósito \& Duarte (2010), as ferramentas para gestão de segurança surgem como de grande valia para manutenção dos empreendimentos, na conciliação de interesses econômicos e ambientais.

Em contramão ao cuidado que se deve ter com os empreendimentos impactantes, o novo conjunto legal busca acelerar o processo de licenciamento ao tentar reduzir os pedidos de complementação pelos órgãos ambientais a uma única solicitação (COPAM, 2017) e ao estabelecer que, uma vez findado o prazo para análise sem que ela tenha sido concluída, o processo vá para a decisão sem análise técnica (Minas Gerais, 2016a). Os pedidos de complementação são essenciais já que, no Brasil, com muita frequência, a qualidade dos EIAs é muito ruim (vide MPF, 2004; Veronez, 2018), de modo que o pedido de informação complementar é primordial para que a análise da viabilidade seja feita de maneira adequada e com qualidade. Em relação ao tempo de análise, há que se considerar as limitações institucionais (quadro de pessoal, acúmulo de processos, pressões), que fazem com que cumprir o prazo, por vezes, não seja um aspecto tão simples (Morgan, 2012).

Com relação à decisão sobre o LA, os processos não apoiados em AIA continuam sendo decididos pela SEMAD. No entanto, a decisão sobre processos apoiados em AIA passou a ser dividida entre COPAM e SEMAD, dependendo da combinação entre potencial poluidor/degradador e porte do empreendimento. Deste modo, menos atividades passaram a ser decididas pelo COPAM e, além disso, não há mais participação das URCs. Uma das implicações disso é que há um momento a menos de participação da sociedade no processo de decisão, além das reuniões das câmaras técnicas acontecerem em Belo Horizonte, o que pode significar um afastamento das regiões afetadas pela atividade e o desconhecimento dos membros das câmaras técnicas em relação à realidade da região impactada, diferente do que ocorria quando a decisão era tomada pelas URCs do COPAM. Reduzir uma forma de participação da sociedade é prejudicial ao processo já que o envolvimento do público na tomada de decisão é um componente fundamental da AIA (Hartley \& Wood, 2005). 
Quanto ao monitoramento, que pode ser considerado o elemento que pode transformar um estudo ambiental de um processo estático em dinâmico, preenchendo a lacuna entre os estudos ambientais e a efetivação e administração de um projeto (Noble \& Storey, 2005), ocorreram duas modificações principais: a dispensa de renovação de LO para algumas atividades e a criação do NUCAM. Os empreendimentos dispensados de renovação de LO estão associados a atividades cujos impactos negativos significativos estão concentrados na fase de construção e, além disso, "a dispensa de renovação de licença não exime o empreendedor quanto à manutenção das obrigações de controle ambiental do empreendimento, durante sua operação" (COPAM, 2017). Assim, isto poderia ser uma forma de concentrar esforços em monitorar impactos de empreendimentos que têm significativo potencial de causar impactos na fase de operação. Por outro lado, é importante destacar que, conhecendo as limitações do órgão ambiental, é necessário acompanhar se de fato essa fiscalização ao longo da operação será intensificada, pois, caso contrário, o fato de dispensar a renovação da LO terá um efeito negativo, visto que se perde um momento de avaliar o desempenho das ações mitigadoras da atividade.

Corroborando esta ideia, cabe destacar que o monitoramento ambiental em MG tem sido considerado deficiente por diversos trabalhos acadêmicos, entre eles Prado Filho \& Souza (2004), Queiroz \& Almeida (2016) e Santiago et al. (2016). Diante desta situação e pensando em melhorias, foi criado pelo Decreto Estadual 47.042/2016 um núcleo focado no monitoramento e fiscalização, o NUCAM. Segundo Oliveira \& Almeida (2019), a implementação do NUCAM é vista com boas expectativas entre os servidores que vislumbram melhores resultados para a fase de pós-licenciamento; no entanto, é cedo para afirmar que os problemas da etapa de monitoramento serão sanados, pois este núcleo carrega os problemas estruturais da SEMAD, como, por exemplo, o número reduzido de servidores.

Finalizando as considerações sobre as mudanças legais, cabe destacar o aumento do número de cidades que passaram a realizar o licenciamento municipal em função de menores exigências da legislação mineira para que os municípios exerçam sua competência. Os municípios que celebraram convênios de cooperação administrativa e técnica com o estado, dentro do que estabelecia a DN COPAM 102/2006, foram a capital Belo Horizonte, Betim, Brumadinho, Contagem, Juiz de Fora, Ibirité e Uberaba (SEMAD, 2018c). No ano de 2018, a cidade de Extrema também celebrou convênio com o estado, mediante o Decreto Estadual 46.937/2017. E, a partir de 2017 até novembro de 2018, com a DN COPAM 213/2017 (alterada pela DN COPAM 219/2018), 60 novos municípios começaram a realizar o licenciamento de acordo com sua competência originária (SEMAD, 2018c).

O licenciamento municipal tem sido bastante controverso na literatura que aponta que entre seus pontos positivos estariam o fato das autoridades locais estarem mais próximas do ambiente e da comunidade afetada, o que resultaria em melhores processos de identificação, mitigação e compensação dos impactos ambientais e, consequentemente, em melhoria na sua efetividade (Strengers, 2004), além do aumento da agilidade no processo e da participação pública por meio dos conselhos municipais de meio ambiente (Nascimento \& Fonseca, 2016). Entretanto, fatores como falta de pessoal treinado, falta de recursos e competências, interferências políticas, prevalência de interesses econômicos e 
falta de articulação setorial se apresentam como barreiras para este tipo de licenciamento (Azevedo et al., 2007). Logo, é preciso tempo para verificar na prática como tem sido o desempenho dos municípios licenciadores para afirmar que o LA local é positivo ou negativo.

Nota-se, assim, que algumas das alterações trazidas pelas novas normas legais que regem o LA e a AIA em MG estão alinhadas com algumas das propostas de simplificação que têm sido discutidas para âmbito nacional, por exemplo, por meio das propostas da ABEMA (2013) e da CNI (2013). Neste sentido, destaca-se o uso de procedimentos eletrônicos; a inclusão de critérios locacionais para a triagem; ampliação das situações em que se dispensa o empreendimento do licenciamento trifásico, favorecendo a prática do licenciamento em duas ou uma única etapa; dispensa da renovação da licença em algumas situações. Simplificações similares em relação à redução dos casos sujeitos à AIA também ocorreram em diferentes países, como Canadá, Reino Unido, África do Sul e Austrália (Gibson, 2012; Bond et al., 2014).

Porém, outros aspectos destacados como de grande relevância para o aprimoramento do sistema de LA, tanto pelos documentos da ABEMA(2013) e da CNI (2013) como pela literatura (e.g. Fonseca et $a l$. ,2017), não foram contemplados pelas alterações ocorridas em MG ou foram alterados de maneira inversa ao que se apresenta como boa prática. Neste sentido, destaca-se que houve a redução da participação pública (por meio da retirada da competência de decisão do COPAM em algumas situações), indo na contramão do que se tem discutido em relação à importância de aumentar as formas de participação e transparência (Glucker et al., 2013; Duarte et al., 2017). Além disso, as alterações não contemplaram nenhuma ação no sentido de aprimorar a definição do escopo e elaboração do TR, tampouco para melhorar a integração do LA com outros instrumentos de planejamento, que são aspectos que têm sido apontados como importantes para uma melhor efetividade do LA e da AIA (Gallardo \& Bond, 2011; Morrison-Saunders et al., 2014; Almeida \& Montaño, 2017).

Vale mencionar, ainda, que um dos aspectos que tem sido apresentado pelos variados atores como necessário para a melhoria da efetividade dos sistemas de LA é o aprimoramento dos órgãos ambientais (capacitação técnica, número de funcionários, recursos disponíveis, melhoria dos sistemas utilizados) (Fonseca et al., 2017; Veronez, 2018). Apesar de esse não ter sido um aspecto analisado neste artigo, é importante destacar que a efetividade de algumas das alterações trazidas pelas novas normas legais depende direta ou indiretamente da capacidade institucional dos órgãos ambientais, por exemplo, o trabalho do NUCAM e a solicitação de informações complementares e análise técnica em acordo com as regras e prazos definidos.

Por fim, vale ressaltar a importância de acompanhar os resultados decorrentes das novas normas legais visto que, ao mesmo tempo em que algumas das alterações já eram percebidas como necessárias para o sistema mineiro (Fonseca \& Rodrigues, 2017), simplificações relacionadas, por exemplo, as reduções dos casos sujeitos à AIA e redução das oportunidades para participação pública, têm sido associadas a redução de benefícios da AIA em alguns contextos (Bond et al., 2014). Nesse sentido, o acompanhamento da efetividade do licenciamento segundo as novas normas legais de MG é fundamental para que seja possível analisar se tais modificações possibilitam maior agilidade e eficiência ao sistema sem acarretar prejuízos à qualidade ambiental. 


\section{Considerações finais}

Alinhado ao contexto de modificações e simplificação dos sistemas de AIA observado no âmbito internacional e nacional, $\mathrm{MG}$ promoveu nos últimos anos um conjunto de alterações nas normas legais que regem a AIA e o LA no estado, alterações essas que foram objeto de análise neste artigo. A partir da análise das normas legais atuais e antigas identificaram-se alguns avanços, destacando-se o uso de recursos digitais e da internet para solicitação da LA e como ferramenta para audiência pública, a inclusão de critérios locacionais na triagem, a alteração de parâmetros para definição do porte das atividades que eram inadequados e a criação de um núcleo voltado para atividades de fiscalização e monitoramento. Essas mudanças estão alinhadas com algumas das propostas de alteração do LA no âmbito nacional e com boas práticas trazidas pela literatura. Espera-se, então, que tragam maior eficiência ao processo de LA mineiro.

Outras alterações, porém, precisarão ser observadas com mais cautela e ao longo do tempo, a fim de melhor compreender seus efeitos em relação à análise da viabilidade ambiental e, por consequência, à efetividade do LA e à qualidade do ambiente. Dentre essas alterações, vale ressaltar a dispensa da renovação da licença de operação para algumas atividades, a diminuição da participação do COPAM na etapa de tomada de decisão e o significativo aumento das situações que passam a ficar sujeitas apenas à LAS, modalidade em que ou não há análise técnica nenhuma (LAS/Cadastro) ou há análise técnica simplificada, sem avaliação dos impactos ambientais (LAS/RAS).
Reforça-se, assim, a necessidade de acompanhar a prática do LA e da AIA no estado, de modo que se possa verificar sua conformidade com os objetivos desses instrumentos e seus efeitos em relação à garantia da proteção ambiental.

\section{Referências}

ABEMA - Associação Brasileira de Entidades Estaduais de Meio Ambiente. Novas propostas para o licenciamento ambiental no Brasil. Associação Brasileira de Entidades Estaduais de Meio Ambiente (ABEMA). Brasília, 2013.

Almeida, M. R. R. Aplicação da abordagem sistêmica para análise da efetividade da Avaliação de Impacto Ambiental no Brasil: um estudo para os estados de São Paulo e Sul de Minas Gerais. São Carlos, Tese (Doutorado em Ciências da Engenharia Ambiental) - EESC/USP, 2013.

Almeida, M. R. R.; Montaño, M. Benchmarking na avaliação de impacto ambiental: O sistema mineiro frente às melhores práticas internacionais. Sociedade \& Natureza, 27(1), 81-96, 2015.

Almeida, M. R. R.; Montaño, M. A efetividade dos sistemas de Avaliação de Impacto Ambiental nos estados de São Paulo e Minas Gerais. Ambiente \& Sociedade, XX(2), 79-106, 2017.

Aversa, I. C. Avaliação de impacto ambiental aplicada a projetos de geração de energia eólica: o caso do Estado do Ceará. São Carlos, Dissertação (Mestrado em Ciências da Engenharia Ambiental) - EESC/USP, 2018.

Azevedo, A.; Pasquis, R.; Bursztyn, M. A reforma do Estado, a emergência da descentralização e as políticas ambientais. Revista do Serviço Público, 58(1), 7-55, 2007.

Bond, A.; Pope, J.; Morrisson-Saunders, A.; Retief, F.; Gunn, J. A. E. Impact assessment: Eroding benefits through streamlining? Environmental Impact Assessment Review, 45, 46-53, 2014.

Braga, D. B. Tecnologia e participação social no processo 
de produção e consumo de bens culturais: novas possibilidades trazidas pelas práticas letradas digitais mediadas pela Internet. Trabalhos em Linguística Aplicada, 49(2), 373-391, 2010.

Bragagnolo, C.; Lemos, C. C.; Ladle, R. J.; Pellin, A. Streamlining or sidestepping? Political pressure to revise environmental licensing and EIA in Brazil. Environmental Impact Assessment Review, 65, 86-90, 2017.

Brasil. Lei ${ }^{\circ} 6.938$, de 31de agosto de 1981. Institui a Política Nacional do Meio Ambiente. Brasília: DOU de 2/9/1981.

Brasil. Lei Complementar $n^{\circ} 140$, de 08 de dezembro de 2011. Brasília: DOU de 9/12/ 2011.

César, P. S. M.; Carneiro, R. A gestão ambiental em Minas Gerais: uma análise do sistema de gestão ambiental e do rompimento da barragem de rejeitos em Mariana. Revista Livre de Sustentabilidade e Empreendedorismo, 2(2), 92217, 2017.

CNI - Confederação Nacional da Indústria. Proposta da Indústria para o Aprimoramento do Licenciamento Ambiental. Confederação Nacional da Indústria (CNI). Brasília, 2013.

CONAMA - Conselho Nacional do Meio Ambiente. Resolução $n^{\circ}$ 01, de 23de janeiro de 1986. Brasília: DOU de 17/2/1986.

CONAMA - Conselho Nacional do Meio Ambiente. Resolução $n^{\circ}$ 237, de 19 de dezembro de 1997. Brasília: DOU de 19/12/1997.

COPAM - Conselho Estadual de Política Ambiental. Deliberação Normativa $n^{\circ} 12$, de 13 de dezembro de 1994. Belo Horizonte: Minas Gerais de 23/12/1994.

COPAM - Conselho Estadual de Política Ambiental. Deliberação Normativa $n^{\circ}$ 074, de 09 de setembro de 2004. Belo Horizonte: Minas Gerais de 2/10/2004.

COPAM - Conselho Estadual de Política Ambiental. Deliberação Normativa $n^{\circ} 102$, de 30 de outubro de 2006. Belo Horizonte: Minas Gerais de 1/11/2006.

COPAM - Conselho Estadual de Política Ambiental. Deliberação Normativa $n^{\circ}$ 217, de 06 de dezembro de 2017. Belo Horizonte: Minas Gerais de 8/12/ 2017.

COPAM - Conselho Estadual de Política Ambiental. De- liberação Normativa $n^{\circ} 225$, de 25 de julho de 2018. Belo Horizonte: Minas Gerais de 1/08/ 2018.

Duarte, C.G.; Dibo, A. P. A.; Siqueira-Gay, J.; Sánchez, L. E. Practitioners' perceptions of the Brazilian environmental impact assessment system: results from a survey. Impact Assessment and Project Appraisal, 35(4), 293-309, 2017.

Elliott, M.; Thomas, I. Environmental impact assessment in Australia: theory and practice. Australia: Federation Press, 3 ed., 2009.

Espósito, T. J.; Duarte, A. P. Classificação de barragens de contenção de rejeitos de mineração e de resíduos industriais em relação a fatores de risco. Revista Escola de Minas, 63(2), 393-398, 2010.

Fernandes, A. H. V.; Cassiano, M. A.; Guimarães, T. C. S.; Almeida, M. R. R. Alternativas locacionais em Avaliação de Impacto Ambiental de rodovias mineiras. Desenvolvimento e Meio Ambiente, 43, 73-90, 2017.

Ferreira, L. M. Do cassete-fórum à Internet: uma proposta educomunicativa para a participação de crianças na mídia. In: Anais do $1^{\circ}$ Congresso Mundial de Comunicação Ibero-Americana da CONFIBERCOM. São Paulo, 2011. Disponível em: $<$ http://confibercom.org/anais2011/pdf/244. pdf $>$. Acesso em: mar. 2019.

FMASE - Fórum de Meio Ambiente do Setor Elétrico. Proposta de Diretrizes Institucionais para o Novo Marco Legal do licenciamento ambiental dos empreendimentos do setor elétrico. Fórum de Meio Ambiente do Setor Elétrico (FMASE). Brasília, 2013.

Fonseca, A.; Rodrigues, S. E. The attractive concept of simplicity in environmental impact assessment: Perceptions of outcomes in southeastern Brazil. Environmental Impact Assessment Review, 67, 101-108, 2017.

Fonseca, A.; Sánchez, L. E.; Ribeiro, J. C. J. Reforming EIA systems: A critical review of proposals in Brazil. Environmental Impact Assessment Review, 62, 90-97, 2017.

Gallardo, A. L. C. F.;Bond, A. Investigating the effectiveness of environmental assessment of land use change: A comparative study of the approaches taken to perennial biomass crop planting in São Paulo and England. Biomass and Bioenergy, 35(5), 2285-2297, 2011. 
Gibson, R. B. In full retreat: the Canadian government's new environmental assessment law undoes decades of progress. Impact Assessment and Project Appraisal, 30(3), 179-188, 2012.

Glucker, A. N.; Driessen, P. P. J.; Kolhoff, A.; Runhaar, H. A. C. Public participation in environmental impact assessment: why, who and how? Environmental Impact Assessment Review, 43, 104-111, 2013.

Hartley, N.; Wood, C. Public participation in environmental impact assessment: implementing the Aarhus Convention. Environmental Impact Assessment Review, 25, 319-340, 2005.

IAIA - International Association for Impact Assessment. Principles of environmental impact assessment best practice. Fargo: IAIA, Special Publication v.1, 1999.

Kennedy, A. J.; Ross, W. A. An approach to integrate impact scoping with environmental impact assessment. Environmental Management, 16(4), 475-484, 1992.

Lawrence, D.P. Environmental Impact Assessment: Practical Solutions to Recurrent Problems and Contemporary Challenges. Hoboken: John Wiley \& Sons, 2013.

Minas Gerais. Lei $n^{\circ} 21.972$, de 21 de janeiro de 2016. Belo Horizonte: Minas Gerais de 21/1/2016a.

Minas Gerais. Decreto $n^{\circ} 46.937$, de 21 de janeiro de 2016. Belo Horizonte: Minas Gerais de 22/1/ 2016b.

Minas Gerais. Decreto ${ }^{\circ}$ 47.042, de 06 de setembro de 2016. Belo Horizonte: Minas Gerais de 22/1/ 2016c.

Minas Gerais. Lei $n^{\circ} 22.257$, de 27 de julho de 2016. Belo Horizonte: Minas Gerais de 21/1/2016d.

Minas Gerais. Lei no 22.291, de 19 de setembro de 2016. Belo Horizonte: Minas Gerais de 21/1/2016e.

Minas Gerais. Decreto $n^{\circ} 47.383$, de 02 de merco de 2018. Belo Horizonte: Minas Gerais de 3/3/2018.

Morgan, R. K. Environmental impact assessment: the state of the art. Impact Assessment and Project Appraisal, 30(1), 5-14, 2012.

Morrison-Saunders, A.; Pope, J.; Gunn, J.; Bond, A.; Retief, F. Strengthening impact assessment: a call for integration and focus. Impact Assessment and Project Appraisal, 32, 2-8, 2014.

Morrison-Saunders, A.; Bond, A.; Pope, J.; Retief, F. Demonstrating the benefits of impact assessment for proponents. Impact Assess. Impact Assessment and Project Appraisal, 33, 108-115, 2015.

MPF - Ministério Público Federal. Deficiências em Estudos de Impacto Ambiental: sintese de uma experiência. Brasília: $4^{\mathrm{a}}$ Câmara de Coordenação e Revisão, Escola Superior do Ministério Público da União, 2004.

Nascimento, T. R. S.; Fonseca, A.Opinião de gestores e analistas ambientais sobre a municipalização do licenciamento ambiental: uma sondagem nacional. In: Anais do $3^{\circ}$ Congresso Brasileiro de Avaliação de Impacto. Ouro Preto, 2016.

Noble, B.; Storey, K.Towards increasing the utility of follow-up in Canadian EIA. Environmental Impact Assessment Review, 25, 63-180, 2005.

Oliveira, F. S. D.; Prado Filho, J. F.; Rocha, C. F.; Fonseca, A. Licenciamento ambiental simplificado na região sudeste brasileira: conceitos, procedimentos e implicações. Desenvolvimento e Meio Ambiente, 38, 461-479, 2016.

Oliveira, R. S.; Almeida, M. R. R. Percepções sobre o licenciamento ambiental e expectativas sobre a atuação do Núcleo de Controle Ambiental na etapa de monitoramento no Estado de Minas Gerais. Revista Brasileira de Gestão Ambiental e Sustentabilidade, 6(12), 117-128, 2019.

Pope, J.; Bond, A.; Morrison-Saunders, A.; Retief, F. Advancing the theory and practice of impact assessment: setting the research agenda. Environmental Impact Assessment Review, 41, 1-9, 2013.

Prado Filho, J. F.; Souza, M. P. O licenciamento ambiental da mineração no quadrilátero ferrífero de Minas Gerais - uma análise da implementação de medidas de controle ambiental formuladas em EIAs/RIMAs. Engenharia Sanitária Ambiental, 9(4), 343-349, 2004.

Queiroz, R. F. P.; Almeida, M. R. R. Mitigação e monitoramento em processos de Licenciamento ambiental de empreendimentos Sucroalcooleiros no Triângulo Mineiro. Geociências, 35(1), 102-109, 2016. 
Rocha, C. P. F.; Machado, F. L. V.; Orquetti, Z. S. C. T. Reforma do sistema estadual de licenciamento ambiental de Minas Gerais: desafios e propostas de melhoria das etapas de triagem e escopo. In: Anais do $3^{\circ}$ Congresso Brasileiro de Avaliação de Impacto. Ouro Preto, 2016.

Rocha, C. P. F.; Fonseca, A. EIA screening criteria in Brazil: a logical test? In: 34th Annual Conference of the International Association for Impact Assessment. Viña Del Mar, 2014. Disponível em: $<$ http://citeseerx.ist.psu.edu/viewdoc/ download?doi=10.1.1.565.1493\&rep=rep1\&type=pdf $>$. Acesso: mar. 2019.

Sánchez, L. E. Avaliação de impacto ambiental: conceitos e métodos. $2^{\mathrm{a}}$ ed. São Paulo: Oficina de Textos, 2013.

Santiago, C. S.; Alvarenga, M. I. N.; Almeida, M. R. R. Avaliação da etapa de acompanhamento do licenciamento ambiental de abatedouros e laticínios em Minas Gerais. Revista Brasileira de Geografia Física, 9(3), 940-954, 2016.

SEMAD - Secretaria de Estado de Meio Ambiente e Desenvolvimento Sustentável. Instrução de Serviço SISEMA 01/2018. 2018a. Disponível em: <http:// www.meioambiente.mg.gov.br/images/stories/2018/ PADRONIZA $\%$ C3\%87\%C3\%83O_PROCEDIMENTOS/ Instru $\% \mathrm{C} 3 \% \mathrm{~A} 7 \% \mathrm{C} 3 \% \mathrm{~A} 30 \_d e \_S e r v i \% \mathrm{C} 3 \% \mathrm{~A} 7 \mathrm{o} \_$Sisema_01.2018_-_Atualizada.pdf $>$. Acesso em: set. 2019.

SEMAD - Secretaria de Estado de Meio Ambiente e Desenvolvimento Sustentável. Sistema de Requerimento de Licenciamento Ambiental. 2018b. Disponível em: <http:// licenciamento.meioambiente.mg.gov.br/site/index $>$. Acesso em: jan. 2019.
SEMAD - Secretaria de Estado de Meio Ambiente e Desenvolvimento Sustentável. Licenciamento Ambiental Municipal. 2018c. Disponível em: <http://www.meioambiente. mg.gov.br/regularizacao-ambiental/regularizacao-ambiental-municipal>. Acesso em: nov. 2018.

SEMAD - Secretaria de Estado de Meio Ambiente e Desenvolvimento Sustentável. Orientações para preenchimento do Formulário de Caracterização do Empreendimento - FCE. 2019a. Disponível em: <http://licenciamento. meioambiente.mg.gov.br/arquivos/manual-fce-eletronico. pdf>. Acesso em: fev. 2019.

SEMAD - Secretaria de Estado de Meio Ambiente e Desenvolvimento Sustentável. Termos de referência. 2019 b. Disponível em: < http://www.meioambiente.mg.gov.br/ regularizacao-ambiental/termos-de-referencia $>$. Acesso em: abr. 2019.

Strengers, Y. Environmental culture change in local government: A practised perspective from the International Council for Local Environmental Initiatives - Australia/ New Zealand. Local Environment, 9(6), 621-628, 2004.

Toth, M.; Mertens, F.; Makiuchi, M. F. R. Novos espaços de participação social no contexto do desenvolvimento sustentável - as contribuições da Educomunicação. Ambiente \& Sociedade, 15(2), 113-132, 2012.

Veronez, F. A. Efetividade da avaliação de impacto ambiental de projetos no Estado do Espírito Santo. 2018. 214 f. São Carlos, Tese (Doutorado em Ciências da Engenharia Ambiental) - EESC/USP, 2018. 